\title{
Chlorogenic acid suppresses lipopolysaccharide-induced nitric oxide and interleukin-1 $\beta$ expression by inhibiting JAK2/STAT3 activation in RAW264.7 cells
}

\author{
SANG-HUN KIM, SUN-YOUNG PARK, YOUNG-LAN PARK, \\ DAE-SEONG MYUNG, JONG-SUN REW and YOUNG-EUN JOO \\ Department of Internal Medicine, Chonnam National University Medical School, \\ Dong-Ku, Gwangju 501-757, Republic of Korea
}

Received August 4, 2016; Accepted August 3, 2017

DOI: $10.3892 / \mathrm{mmr} .2017 .7686$

\begin{abstract}
Chlorogenic acid (CA) is a phenolic compound purified from coffee, fruits and their associated beverages, which possess various biological properties, such as antioxidant and anticarcinogenic activities. The present study evaluated the effects of CA on lipopolysaccharide (LPS)-induced inflammation in RAW264.7 cells and the associated intracellular signaling pathways using reverse transcription-quantitative polymerase chain reaction, western blotting and enzyme-linked immunosorbent assays. CA pretreatment inhibited LPS-induced expression of inducible nitric oxide synthase (iNOS), nitric oxide (NO) and pro-inflammatory mediators including interleukin (IL)-6, tumor necrosis factor- $\alpha$ (TNF- $\alpha$ ), macrophage inflammatory protein-2 (MIP-2) and IL-1 $\beta$ in RAW264.7 cells. In addition, phosphorylation of Janus kinase 2/signal transducer and activator of transcription 3 (JAK2/STAT3) with LPS was inhibited by CA pretreatment. CA and STAT3 inhibitor (STAT3i) pretreatment inhibited LPS-induced nuclear translocation of phosphorylated STAT3. In addition, STAT3i inhibited the LPS-induced expression of iNOS, NO and IL-1 $\beta$ similar to the results of CA pretreatment. By contrast, STAT3i did not inhibit the LPS-induced increase in IL-6, TNF- $\alpha$ and MIP-2 expression. These results indicate that CA may suppress LPS-induced NO and IL-1 $\beta$ expression by inhibiting JAK2/STAT3 activation in RAW264.7 cells.
\end{abstract}

Correspondence to: Professor Young-Eun Joo, Department of Internal Medicine, Chonnam National University Medical School, 8, Hak-Dong, Dong-Ku, Gwangju 501-757, Republic of Korea E-mail: yejoo@chonnam.ac.kr

Key words: chlorogenic acid, inflammation, nitric oxide, interleukin-1 $\beta$, Janus kinase 2/signal transducer and activator of transcription 3 signaling

\section{Introduction}

Naturally occurring dietary compounds derived from medicinal plants serve important roles against inflammation and cancer (1-3). Coffee, the most commonly consumed beverage worldwide, is a rich source of dietary phenolic phytochemicals (4). Epidemiological studies have indicated that the dietary intake of coffee lowers the risk of developing cardiovascular disorders, diabetes, Parkinson's disease and cancer of the colon, liver, breast, prostate and endometrium (5-7).

Chlorogenic acid (CA) is one of the most abundant phenolic phytochemicals purified from various plants, fruits and beverages, such as coffee. Previous in vitro and in vivo studies have reported that CA demonstrates significant anti-inflammatory, antioxidative and anticarcinogenic effects (8-10). This suggests that the use of CA may be a useful strategy for the treatment and/or control of inflammation and cancer. However, the underlying molecular mechanisms and targets responsible for the health benefits of CA remain unknown.

Although the pathogenesis of inflammatory bowel disease (IBD) has not yet been elucidated, the currently accepted pathogenic scenario suggests that IBD may occur as a result of dysregulated innate and adaptive immune responses against the commensal gut flora, thus generating an excessive production of pro-inflammatory mediators (11). As part of the dysregulated immune response, macrophages serve a major role in IBD (12-14).

Lipopolysaccharide (LPS), a component of Gram-negative bacterial cell walls, is involved in the barrier function of the intestinal epithelium and activates the immune system, leading to the production of pro-inflammatory mediators, including nitric oxide (NO), enzymes including interleukin-1-receptor-associated kinases or interleukin-receptor-associated kinases (IRAKs), inflammatory cytokines, chemokines and adhesion molecules $(15,16)$. The production of pro-inflammatory mediators induced by LPS has been implicated in the activation of a number of signaling pathways involving the phosphorylation of Janus kinase/signal transducer and activator of transcription (JAK/STAT), mitogen-activated protein kinases (MAPKs) and nuclear factor- $\kappa \mathrm{B}(\mathrm{NF}-\kappa \mathrm{B})$. Among LPS-induced signaling pathways, the JAK/STAT pathway is crucial for the expression 
of pro-inflammatory mediators, including inducible nitric oxide synthase (iNOS), NO and interleukin (IL)-1 $\beta$ (17-19). Thus, activation of JAK/STAT serves a critical role in inflammation-associated injuries, such as IBD, and has been proposed to be a major causative event and therapeutic target for IBD $(20,21)$. In addition, the use of a JAK/STAT inhibitor is being investigated as a target immunomodulator for IBD treatment $(22,23)$.

The aim of the present study was to evaluate the effects of CA on LPS-induced inflammation and its associated intracellular signaling pathway in macrophages.

\section{Materials and methods}

Cell culture. RAW264.7 murine macrophage-like cells were obtained from the American Type Culture Collection (Manassas, VA, USA; ref. no. CRL-1589). The cells were cultured in Dulbecco's modified Eagle's medium (Hyclone; GE Healthcare Life Sciences, Logan, UT, USA) supplemented with $10 \%$ fetal bovine serum (Hyclone; GE Healthcare Life Sciences) and $1 \%(\mathrm{v} / \mathrm{v})$ penicillin/streptomycin (Gibco; Thermo Fisher Scientific, Inc., Waltham, MA, USA) was used at $37^{\circ} \mathrm{C}$ in a humidified atmosphere of $5 \% \mathrm{CO}_{2}$. CA and LPS from Escherichia coli (Serotype 0111:B4) were purchased from Sigma-Aldrich; Merck KGaA (Darmstadt, Germany). STAT3 inhibitor (STAT3i) S3I-201 was obtained from Sigma-Aldrich; Merck KGaA and dissolved in dimethyl sulfoxide (DMSO; Sigma-Aldrich; Merck KGaA). Cells were pretreated with $2 \mathrm{mM}$ CA or $50 \mu \mathrm{M}$ STAT3i prior to stimulation with $100 \mathrm{ng} / \mathrm{ml}$ LPS for $24 \mathrm{~h}$.

Cell viability assay. RAW264.7 cells were plated on a 96-well plate at a density of $1 \times 10^{4}$ cells/well and were incubated for $24 \mathrm{~h}$ at $37^{\circ} \mathrm{C}$ prior to treatment with CA. Cells were then treated with various concentrations of CA $(0,0.05,0.1,0.2,0.5$, 1, $2 \mathrm{mM}$ ) or LPS (50, 100 and $200 \mathrm{ng} / \mathrm{ml})$ for $24 \mathrm{~h}$. Following treatment, cell viability was determined using an EZ-Cytox (WST-1 tetrazolium salt) Colorimetric Cell Viability assay kit (Daeil Lab Service Co., Ltd, Seoul, Republic of Korea) according to the manufacturer's protocols. Following incubation of cells with the WST-1 reagent (100 $\mu \mathrm{l} /$ well) diluted 1:20 for $90 \mathrm{~min}$ at $37^{\circ} \mathrm{C}$, the absorbance at $450 \mathrm{~nm}$ was measured using a microplate reader (Infinite M200; Tecan Trading AG., Männedorf, Switzerland). Each experiment was performed in triplicate wells and repeated at least three times.

Semi-quantitative reverse transcription-polymerase chain reaction (Semi-qRT-PCR). RAW264.7 cells were plated on a 12-well plate at a density of $2 \times 10^{5}$ cells/well, and then treated with $2 \mathrm{mM}$ CA or $100 \mathrm{ng} / \mathrm{ml}$ LPS for 0 to 4 or $16 \mathrm{~h}$. Total RNA was isolated from cells by using the TRIzol ${ }^{\circledR}$ reagent (Invitrogen; Thermo Fisher Scientific, Inc.) according to the manufacturer's protocols. The quantity and purity of total RNA was determined using a NanoDrop spectrophotometer (NanoDrop Technologies, LLC; Thermo Fisher Scientific, Inc., Wilmington, DE, USA). Total RNA (1 $\mu \mathrm{g})$ was reverse transcribed to cDNA using the Moloney murine leukemia virus reverse transcriptase (Promega Corporation, Madison, WI, USA) according to manufacturer's protocols. Semi-qRT-PCR was performed to measure the mRNA level of target genes and
Table I. Primers employed for reverse transcription-quantitative polymerase chain reaction analysis.

\begin{tabular}{ll}
\hline Gene & \multicolumn{1}{c}{ Sequence (5'-3') } \\
\hline $\begin{array}{l}\text { IL-6 } \\
\text { Forward } \\
\text { Reverse }\end{array}$ & GGATACCACCCACAACAGACC \\
TNF- $\alpha$ & GGTCCTTAGCCACTCCTTCTG \\
Forward & GCACAGAAAGCATGATCCGCG \\
Reverse & GACAGAAGAGCGTGGTGGCCC \\
MIP-2 & \\
Forward & GACTTCAAGAACATCCAGAGCT \\
Reverse & GTTAGCCTTGCCTTTGTTCAG \\
IL-1 $\beta$ & \\
Forward & GGAGAACCAAGCAACGACAAA \\
Reverse & TGGGGAACTCTGCAGACTCAAAC \\
iNOS & \\
Forward & CTGCAGCACTTGGATCAGGA \\
Reverse & GAGTAGCCTGTGTGCACCTG \\
COX-2 & CCCACCACCCTGTTGCTGTA \\
Forward & CCTTCTCCAACCTCTCCTACTA \\
Reverse & GATACACCTCTCCACCAATG \\
FAPDH & \\
Revward &
\end{tabular}

IL, interleukin; TNF- $\alpha$, tumor necrosis factor- $\alpha$; MIP-2, macrophage inflammatory protein-2; iNOS, inducible nitric oxide synthase; COX-2, cyclooxygenase-2.

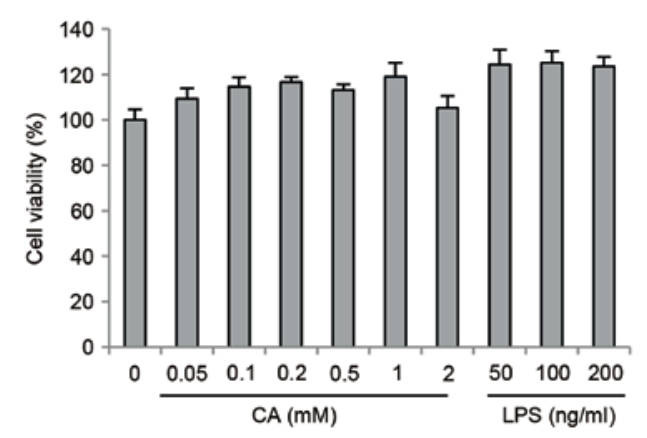

Figure 1. CA does not affect the viability of RAW264.7 cells. RAW264.7 cells were cultured with 0 to $2 \mathrm{mM} \mathrm{CA}$ and 0 to $200 \mathrm{ng} / \mathrm{ml} \mathrm{LPS} \mathrm{for} 24 \mathrm{~h}$. Cell viability was then measured using a WST-1 procedure. Data are presented as the mean \pm standard error of three independent experiments. CA, chlorogenic acid; LPS, lipopolysaccharide.

reference gene (GAPDH) using gene-specific primers (Table I) and the GoTaq DNA Polymerase (Promega Corporation) according to manufacturer's protocols. The Semi-qRT-PCR was performed by initial incubation at $94^{\circ} \mathrm{C}$ for $5 \mathrm{~min}$ followed by 30 cycles of $94^{\circ} \mathrm{C}$ for $20 \mathrm{sec}, 58^{\circ} \mathrm{C}$ for $30 \mathrm{sec}$ and $72^{\circ} \mathrm{C}$ for $30 \mathrm{sec}$, with a final extension step of $72^{\circ} \mathrm{C}$ for $5 \mathrm{~min}$. The PCR products were separated by electrophoresis on a $1 \%$ agarose gel containing ethidium bromide. The signals were quantified by 
A.
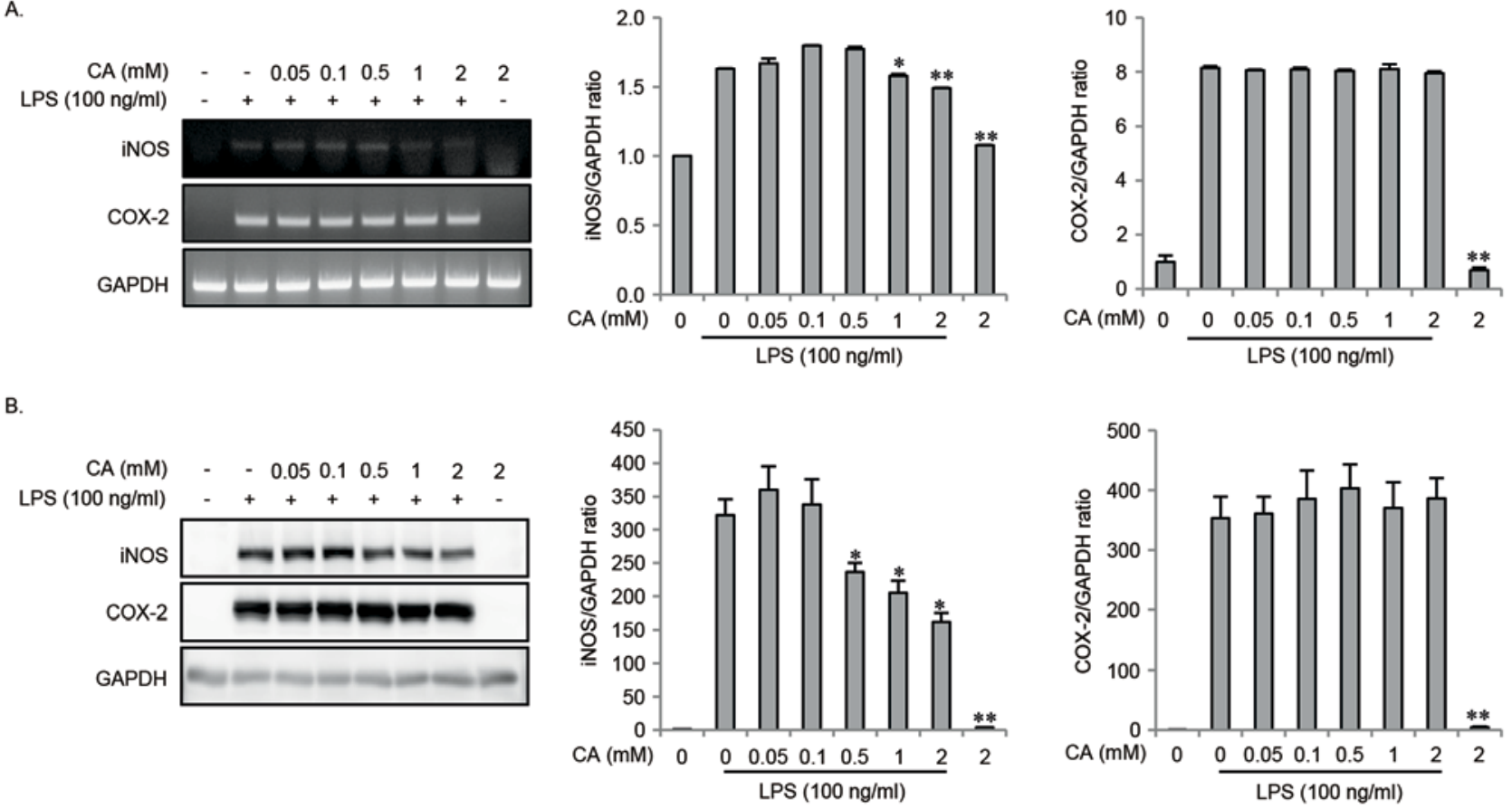

C.

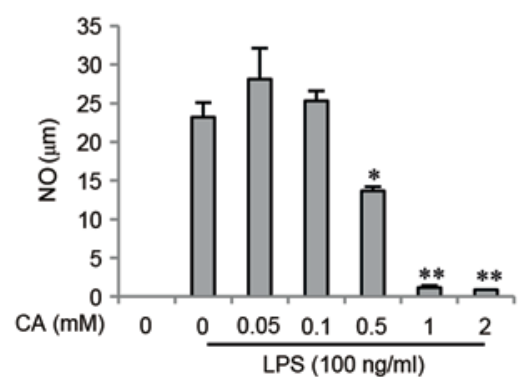

Figure 2. CA inhibits LPS-induced iNOS and NO expression in a dose-dependent manner in RAW264.7 cells. (A) Cells were pretreated with 0.05 to $2 \mathrm{mM}$ $\mathrm{CA}$ for $2 \mathrm{~h}$ and then stimulated with $100 \mathrm{ng} / \mathrm{ml}$ LPS for $16 \mathrm{~h}$ in RAW264.7 cells. Total RNA was isolated and the expression of iNOS and COX-2 was detected by reverse transcription-quantitative polymerase chain reaction. (B) Cell lysates were prepared and subjected to western blotting analysis using anti-iNOS and anti-COX-2 antibodies. (C) Cells were pretreated with 0 to $2 \mathrm{mM} \mathrm{CA}$ for $2 \mathrm{~h}$ followed by stimulation with $100 \mathrm{ng} / \mathrm{ml} \mathrm{LPS}$ for $24 \mathrm{~h}$. The level of NO was measured in the culture medium using Griess reagents. Data is presented as the mean \pm standard deviation. ${ }^{*} \mathrm{P}<0.05$ and ${ }^{* *} \mathrm{P}<0.01$ vs. LPS stimulation alone. CA, chlorogenic acid; LPS, lipopolysaccharide; iNOS, inducible nitric oxide synthase; COX-2, cyclo-oxygenase-2; NO, nitric oxide.

densitometric analysis using Multi-Gauge software version 3.0 (Fujifilm Holdings Corporation). Experiments were performed in triplicate.

Western blot analysis. RAW264.7 cells plated on a 6-well plate at a density of $3 \times 10^{5}$ cells/well and then treated with $2 \mathrm{mM} \mathrm{CA}$ or $100 \mathrm{ng} / \mathrm{ml}$ LPS. Cells were lysed in radioimmunoprecipitation extraction solution containing $1 \mathrm{X} \mathrm{Halt}{ }^{\mathrm{TM}}$ Phosphatase inhibitor and 1X Halt ${ }^{\mathrm{TM}}$ Protease inhibitor cocktail (Thermo Fisher Scientific, Inc.) for $15 \mathrm{~min}$ in an ice bath. The protein concentration of lysates from treated cells was measured using a bicinchoninic protein assay kit (Thermo Fisher Scientific, Inc.) according to the manufacturer's protocols. Equal quantities of protein $(20 \mu \mathrm{g})$ were separated using SDS-PAGE (10-12\%) and transferred to a polyvinylidene difluoride membrane (Bio-Rad Laboratories, Inc., Hercules, CA, USA). Antibodies against the following proteins were employed: iNOS (cat. no. 2977), cyclooxygenase-2 (COX-2; cat. no. 4842), STAT3 (cat. no. 9139), phosphorylated (p)-STAT3 (cat. no. 8336), JAK2 (cat. no. 3230), p-JAK2 (cat. no. 4406), extracellular signal-regulated kinase1/2 (ERK1/2; cat. no. 4695), p-ERK1/2 (cat. no. 4370), p38 (cat. no. 9212), p-p38 (cat. no. 4511), c-Jun NH2-terminal kinase (JNK; cat. no. 9252), p-JNK (cat. no. 4668), nuclear factor of $\kappa$ light polypeptide gene enhancer

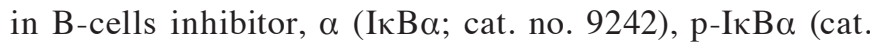
no. 9246), p65 (cat. no. 4764), p-p65 (cat. no. 3033) all from Cell Signaling Technology, Inc. (Danvers, MA, USA), and lamin A (cat. no. sc-20680) and GAPDH (cat. no. sc-25778) from Santa Cruz Biotechnology, Inc. (Dallas, TX, USA). The primary antibodies were diluted 1:1,000 and incubated with membranes for $15 \mathrm{~h}$ at $4^{\circ} \mathrm{C}$. Following a final rinsing with Tris-buffered saline-Tween (TBST) each membrane was incubated with 1:1,000 diluted secondary horseradish peroxidase (HRP)-linked anti-rabbit (cat. no. 7074) or anti-mouse (cat. no. 7076) immunoglobulin (Ig)G from Cell Signaling Technology, Inc. for $1 \mathrm{~h}$ at room temperature. Protein bands were analyzed using an enhanced chemiluminescence detection system (Amersham; GE Healthcare Life Sciences) and the ImageQuant LAS-4000 luminescent image analyzer (Fujifilm Holdings Corporation, Tokyo, Japan) Immunoblots were 
A.
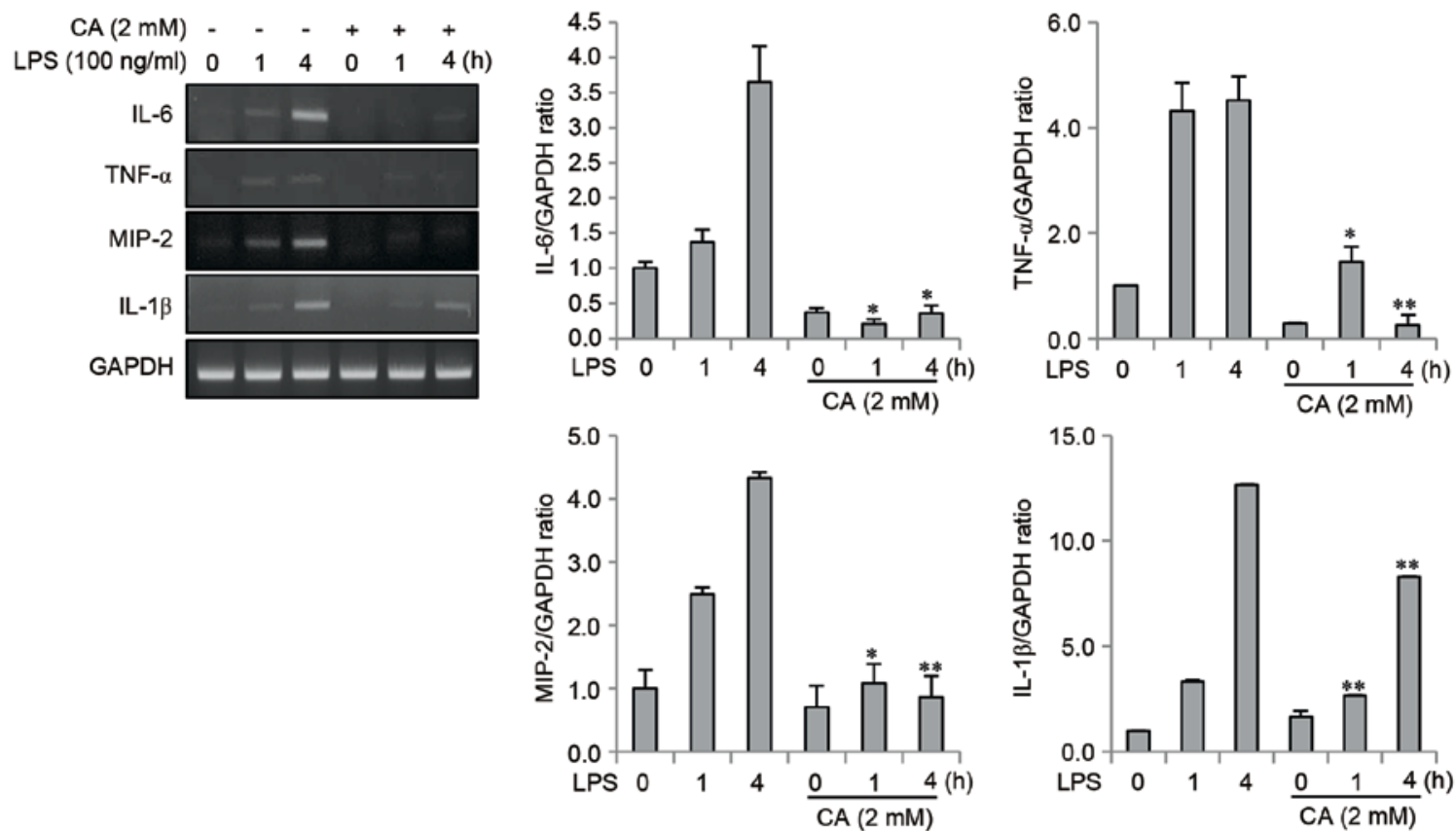

B.
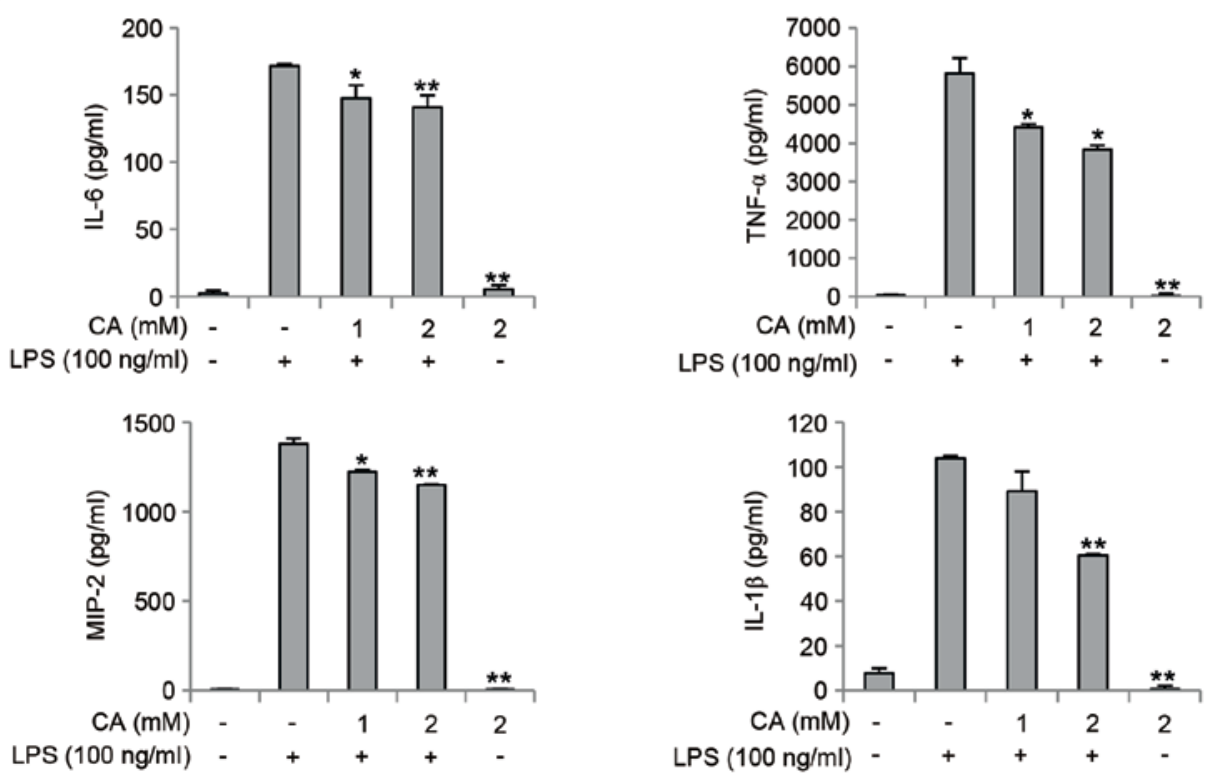

Figure 3. CA inhibits LPS-induced expression of pro-inflammatory mediators in RAW264.7 cells. (A) RAW264.7 cells were pretreated with 2 mM CA for $2 \mathrm{~h}$, followed by stimulation with $100 \mathrm{ng} / \mathrm{ml}$ LPS for 0 to $4 \mathrm{~h}$. Total RNA was isolated using the TRIzol procedure and the expression of IL-6, TNF- $\alpha$, MIP-2 and IL-1 $\beta$ was detected by reverse transcription-quantitative polymerase chain reaction. Gene expression levels were normalized to those of GAPDH. (B) RAW264.7 cells were pretreated with 0,1 or $2 \mathrm{mM} \mathrm{CA}$ for $2 \mathrm{~h}$ prior to stimulation with $100 \mathrm{ng} / \mathrm{ml} \mathrm{LPS}$. Following $24 \mathrm{~h}$, the levels of IL-6, TNF- $\alpha$, MIP-2 and IL- $1 \beta$ in the culture medium were measured using an ELISA kit. ${ }^{*} \mathrm{P}<0.05$ and ${ }^{* *} \mathrm{P}<0.01$ vs. LPS stimulation alone. CA, chlorogenic acid; LPS, lipopolysaccharide; IL, interleukin; TNF- $\alpha$, tumor necrosis factor- $\alpha$; MIP-2, macrophage inflammatory protein-2.

quantified using Multi-Gauge software version 3.0 (Fujifilm Holdings Corporation). Experiments were performed in triplicate.

Determination of IL-6, tumor necrosis factor- $\alpha$ (TNF- $\alpha)$, macrophage inflammatory protein-2 (MIP-2) and IL-1 $\beta$ levels. RAW264.7 cells were plated on a 12-well plate at a density of $2 \times 10^{5}$ cells/well and pretreated with CA (1-2 mM) for $2 \mathrm{~h}$ followed by stimulation with $100 \mathrm{ng} / \mathrm{ml}$ LPS for $24 \mathrm{~h}$. The cell culture medium was then collected and centrifuged at $15,000 \mathrm{x} \mathrm{g}$ at $4^{\circ} \mathrm{C}$ for $7 \mathrm{~min}$. The levels of IL-6, TNF- $\alpha$, MIP-2 and IL- $1 \beta$ in the culture medium were determined using Quantikine ELISA mouse MIP-2 (cat. no. MM200) and mouse IL-1b kits (cat. no. MLB00C) from R\&D Systems Inc. (Minneapolis, MN, USA), and the OptEIA ${ }^{\mathrm{TM}}$ kits for mouse interleukin-6 (IL-6; cat. no. 555240) and mouse TNF (cat. no. 558534) from BD Biosciences (San Jose, CA, USA) according to the manufacturer's protocols. The quantity of IL-6, TNF- $\alpha$, MIP-2 and IL-1 $\beta$ was determined based on the optical density values (read at $450 \mathrm{~nm}$ ) obtained using a Bio-Rad Model 550 Microplate Reader (Bio-Rad Laboratories, Inc.) and a standard curve. Experiments were performed in triplicate. 
A.

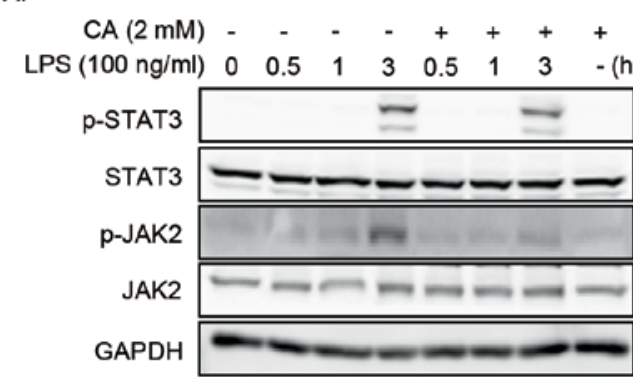

B.

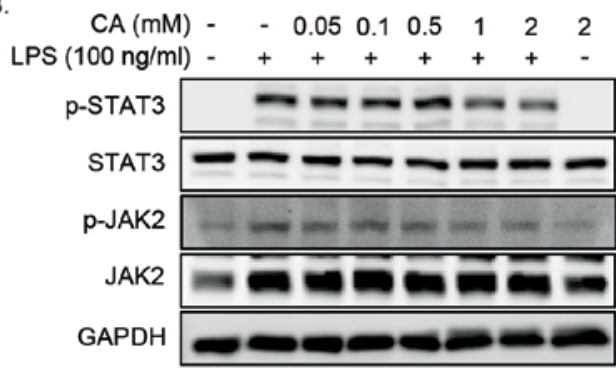

C.

$\mathrm{CA}(2 \mathrm{mM})-\quad-\quad-\quad+\quad+\quad+$

LPS $(100 \mathrm{ng} / \mathrm{ml}) \quad 0 \quad 10 \quad 30 \quad 0 \quad 10 \quad 30$ (Min)

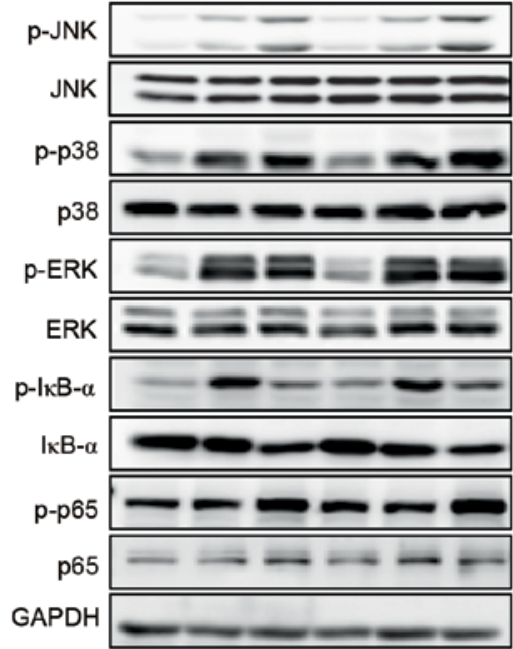

Figure 4. CA inhibits the LPS-induced activation of JAK2 and STAT3 in RAW264.7 cells. (A) Cells were pretreated with $2 \mathrm{mM} \mathrm{CA}$ for $2 \mathrm{~h}$ and then stimulated with $100 \mathrm{ng} / \mathrm{ml}$ LPS for $0,0.5,1$ or $3 \mathrm{~h}$. Cell lysates were prepared and subjected to western blotting analysis. CA pretreatment was associated with decreased levels of p-JAK2 and p-STAT3 at $3 \mathrm{~h}$ following LPS stimulation. (B) RAW264.7 cells were pretreated with 0 to $2 \mathrm{mM}$ CA for $2 \mathrm{~h}$ prior to stimulation with $100 \mathrm{ng} / \mathrm{ml}$ LPS for $3 \mathrm{~h}$. Cell lysates were prepared and subjected to western blotting analysis. CA pretreatment with 1 or $2 \mathrm{mM}$ was associated with a decrease in the level of p-JAK 2 and p-STAT3. (C) Cells were pretreated with 0 or $2 \mathrm{mM} \mathrm{CA}$ for $2 \mathrm{~h}$ prior to stimulation with $100 \mathrm{ng} / \mathrm{ml} \mathrm{LPS} \mathrm{for} 0,10$ or $30 \mathrm{~min}$. Cell lysates were prepared and subjected to western blotting analysis. The levels of p-ERK1/2, p-JNK, p-p38, p-IкB $\alpha$ and p-p65 remained unchanged with CA pretreatment. CA, chlorogenic acid; LPS, lipopolysaccharide; p-STAT3, phosphorylated signal transducer and activator of transcription 3; p-JAK2, phosphorylated Janus kinase 2; p-JNK, phosphorylated c-Jun NH2-terminal kinase; p-ERK, phosphorylated extracellular signal-regulated kinase; p-IkBa, phosphorylated nuclear factor of $\mathrm{k}$ light polypeptide gene enhancer in B-cells inhibitor, $\alpha$.
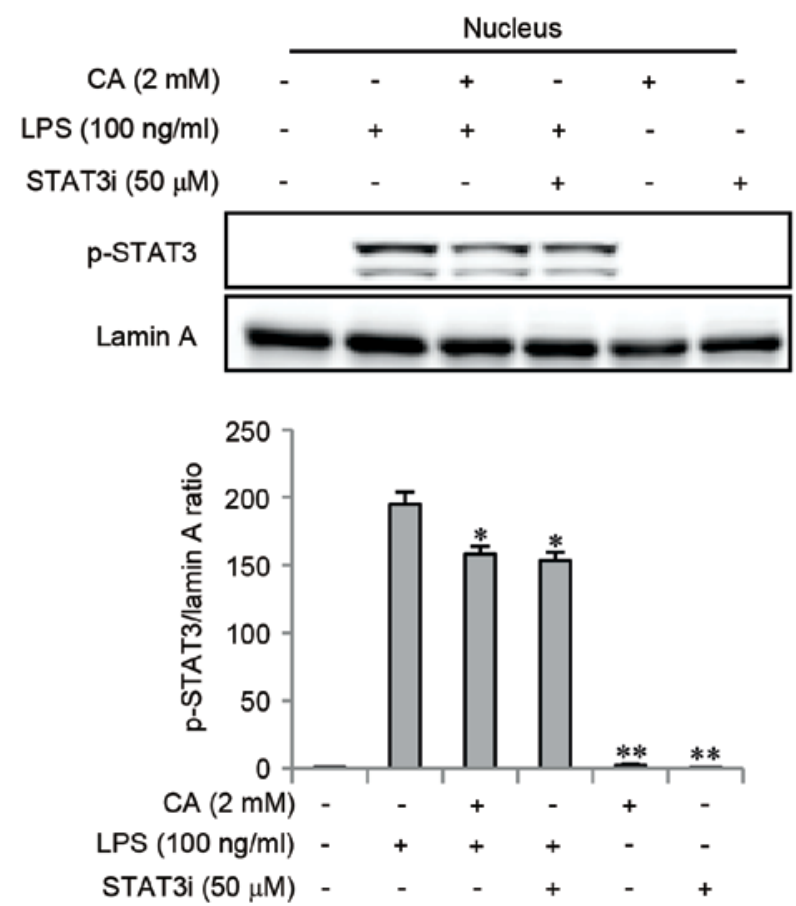

Figure 5. CA inhibits nuclear translocation of p-STAT3 in RAW264.7 cells. RAW264.7 cells were pretreated with $2 \mathrm{mM} \mathrm{CA}$ or STAT3i for $2 \mathrm{~h}$ prior to stimulation with $100 \mathrm{ng} / \mathrm{ml}$ LPS for $3 \mathrm{~h}$. The level of p-STAT3 were determined by western blotting. Protein expression levels were normalized to Lamin A. Data are expressed as the mean \pm standard deviation of three independent experiments. ${ }^{*} \mathrm{P}<0.05$ and ${ }^{* *} \mathrm{P}<0.01$ vs. LPS stimulation alone. CA, chlorogenic acid; STAT3i, STAT3 inhibitor; p-STAT3, phosphorylated signal transducer and activator of transcription 3; LPS, lipopolysaccharide.
NO analysis. RAW264.7 cells were plated on a 12-well plate at a density of $2 \times 10^{5}$ cells/well and pretreated with varying concentrations of CA (0 to $2 \mathrm{mM}$ ) for $2 \mathrm{~h}$ followed by stimulation with $100 \mathrm{ng} / \mathrm{ml}$ LPS for $24 \mathrm{~h}$. NO synthesis was determined by analyzing the level of nitrite in cell culture supernatants using Griess Reagent (1\% sulfanilamide, $0.1 \%$ $\mathrm{N}$-(1-naphthyl)-ethylenediamine dihydrochloride in $5 \%$ phosphoric acid solution) following incubation at room temperature for $30 \mathrm{~min}$. The absorbance was measured at $540 \mathrm{~nm}$ and the nitrite concentration was determined using sodium nitrite as a standard. Three replicates were performed for each of the different treatments.

Preparation of nuclear extracts. RAW264.7 cells were plated on a $60 \mathrm{~mm}$ dish at a density of $2 \times 10^{6}$ cells and pretreated with CA $(2 \mathrm{mM})$ for $2 \mathrm{~h}$ followed by stimulation with $100 \mathrm{ng} / \mathrm{ml}$ LPS for $24 \mathrm{~h}$. The cells were washed with phosphate-buffered saline and lysis the pellet cells by centrifugation at $250 \mathrm{xg}$ for $5 \mathrm{~min}$ at $4^{\circ} \mathrm{C}$. Nuclear protein extracts were prepared using the ProteoJET ${ }^{\mathrm{TM}}$ Cytoplasmic and Nuclear Protein Extraction kit (Fermentas; Thermo Fisher Scientific, Inc., Pittsburgh, PA, USA) according to the manufacturer's protocols.

Statistical analysis. The results are presented as the mean \pm standard deviation. Differences between groups were determined by Student's t-test. The statistical analysis was performed with the SPSS version 15.0 (SPSS, Inc., Chicago, IL, USA). P $<0.05$ was considered to indicate a statistically significant difference. 
A.

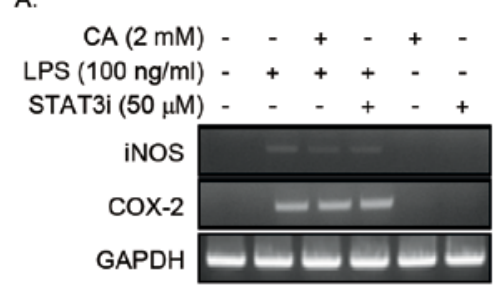

B.

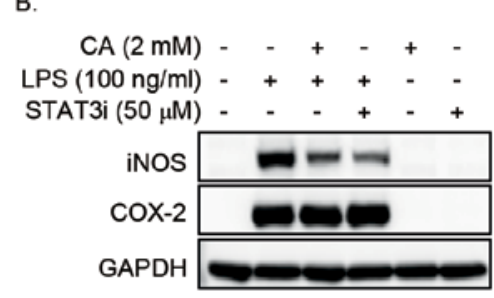

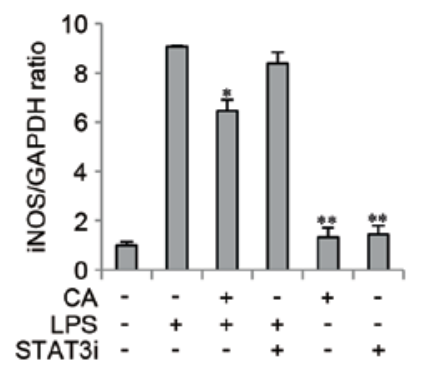

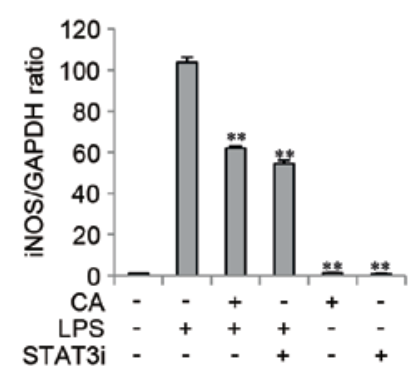

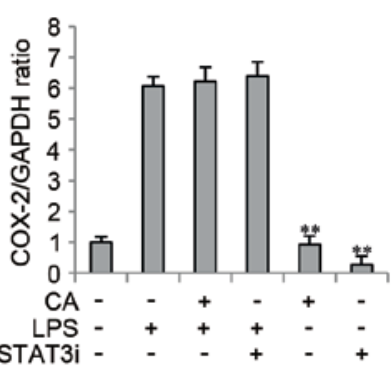

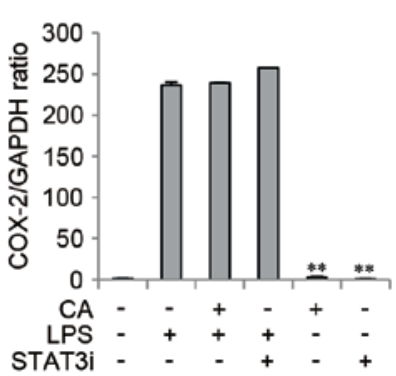

Figure 6. STAT3i suppresses LPS-induced iNOS protein expression, and not COX-2 expression in RAW264.7 cells. RAW264.7 cells were pretreated with $2 \mathrm{mM}$ CA or STAT3i for $2 \mathrm{~h}$, and then stimulated with $100 \mathrm{ng} / \mathrm{ml}$ LPS for 16 or $24 \mathrm{~h}$. (A) CA pretreatment significantly inhibited the LPS-induced expression of iNOS mRNA, whereas CA and STAT3i pretreatment demonstrated no effect on LPS-induced COX-2 mRNA. (B) STAT3i and CA pretreatment inhibited the LPS-induced expression of iNOS protein expression, whereas no effect on LPS-induced COX-2 expression was observed. "P<0.05 and ${ }^{* *} \mathrm{P}<0.01$ vs. LPS stimulation alone. STAT3i, STAT3 inhibitor; LPS, lipopolysaccharide; iNOS, inducible nitric oxide synthase; COX-2, cyclooxygenase-2; CA, chlorogenic acid.

\section{Results}

Impact of CA on the viability of RAW264.7 cells. RAW264.7 cells were treated with CA and LPS at a range of different concentrations (CA, 0 to $2 \mathrm{mM}$; LPS, 0 to $200 \mathrm{ng} / \mathrm{ml}$ ) for $24 \mathrm{~h}$. As shown in Fig. 1, CA and LPS treatment did not exhibit cytotoxic effects on RAW264.7 cells.

Effect of CA on LPS-induced expression of iNOS, NO and COX-2 in RAW264.7 cells. The present study investigated the effects of CA on the expression of iNOS and COX-2 in response to LPS challenge of RAW264.7 cells. The cells were pretreated with varying concentrations of CA for $2 \mathrm{~h}$, and then stimulated with LPS for 16 or $24 \mathrm{~h}$. LPS-induced mRNA and protein expression of iNOS and COX-2 was measured by Semi-qRT-PCR and western blotting. LPS-induced expression of iNOS mRNA and protein was significantly inhibited in a dose-dependent manner by CA pretreatment, whereas COX-2 expression was not (Fig. 2A and B). In addition, LPS-induced NO production was inhibited in a dose-dependent manner by CA pretreatment (Fig. 2C).

Impact of CA on LPS-induced pro-inflammatory mediator expression. The effect of CA on the production of pro-inflammatory mediators was investigated. Cells were pretreated with CA for $2 \mathrm{~h}$, and were then stimulated with LPS for $0,1,4$ or $24 \mathrm{~h}$. CA pretreatment significantly inhibited the LPS-induced expression of IL-6, TNF- $\alpha$, MIP-2 and IL-1 $\beta$ at the mRNA and protein levels (Fig. 3A and B).

Effect of CA on LPS-induced JAK2 and STAT3 activation. The expression of pro-inflammatory mediators is regulated by the activation of the MAPKs, NF- $\mathrm{B}, \mathrm{JAK} 2$ and STAT3 signaling pathways (17). Therefore, the present study determined the effect of CA on the LPS-induced MAPKs, NF- $\kappa$ B, JAK2 and STAT3 by western blotting. Cells were pretreated with specific concentrations of CA for $2 \mathrm{~h}$, prior to stimulation with LPS for various lengths of time. CA pretreatment resulted in a decrease in the level of p-JAK2 and p-STAT3 (Fig 4A and B), whereas the levels of ERK1/2, JNK, p38, I $\kappa \mathrm{B} \alpha$ and p65 remained unchanged (Fig. 4C).

Impact of CA on nuclear translocation of phosphorylated STAT3. A STAT3i was used to determine whether the STAT3 signaling pathway may be involved in the anti-inflammatory effects of CA. Cells were pretreated with CA or STAT3i for $2 \mathrm{~h}$, and then stimulated with LPS for $3 \mathrm{~h}$. The level of p-STAT3 was determined by western blotting. CA and STAT3i pretreatments significantly inhibited LPS-induced nuclear translocation of p-STAT3 (Fig. 5).

Effect of STAT3i on LPS-induced NO and the expression of pro-inflammatory mediators. In order to examine the effect of STAT3 signaling on LPS-induced NO and pro-inflammatory mediator expression, cells were pretreated with CA or STAT3i for $2 \mathrm{~h}$, and then stimulated with LPS for 16 or $24 \mathrm{~h}$. STAT3i pretreatment inhibited the LPS-induced expression of iNOS protein, whereas the LPS-induced mRNA and protein expression of COX-2 remained unchanged (Fig. 6). Pretreatment with CA significantly reduced the LPS-induced expression of iNOS mRNA and protein, whereas no effect on COX-2 mRNA and protein was observed (Fig. 6). In addition, STAT3i pretreatment significantly inhibited the LPS-induced expression of NO and IL-1 $\beta$ when compared to LPS treatment alone (Fig. $7 \mathrm{~A}$ and $\mathrm{B}$ ); however, the expression levels of IL-6, TNF- $\alpha$, and MIP-2 remained unaffected (Fig. 7C-E). Pretreatment with CA significantly inhibited LPS-induced expression of NO and all of the pro-inflammatory mediators investigated (Fig. 7). These 


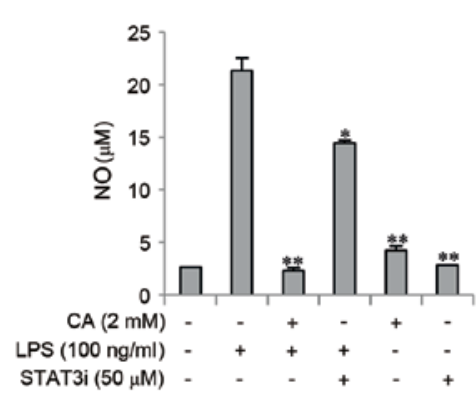

C.

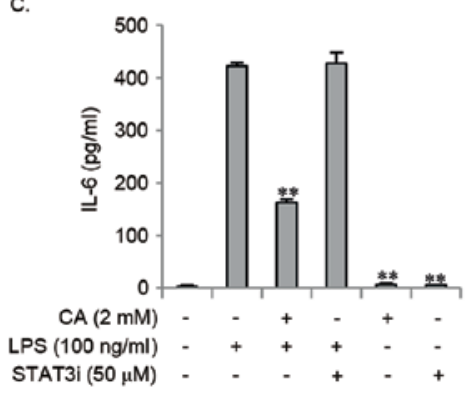

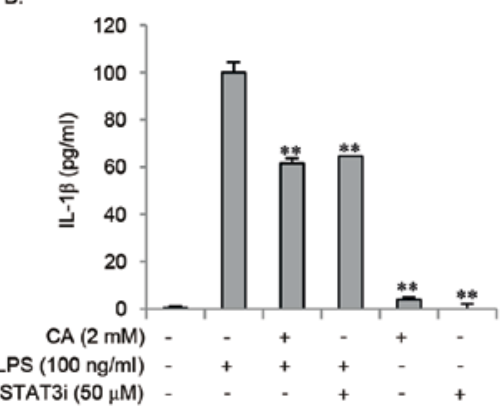

D.

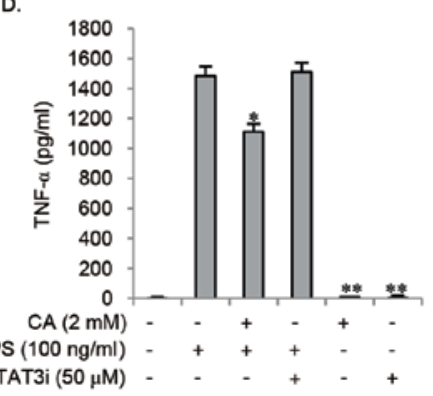

E.

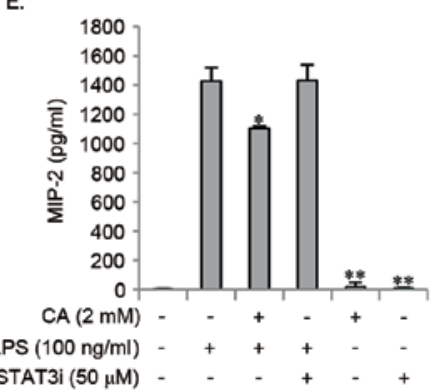

Figure 7. STAT3i inhibited LPS-induced expression of NO and IL-1 $\beta$, and not the expression of IL-6, TNF- $\alpha$ and MIP-2 in RAW264.7 cells. RAW264.7 cells were pretreated with $2 \mathrm{mM}$ CA or STAT3i for $2 \mathrm{~h}$, and then stimulated with $100 \mathrm{ng} / \mathrm{ml}$ LPS for $24 \mathrm{~h}$. The levels of NO, IL-6, TNF- $\alpha$, MIP-2 and IL-1 $\beta$ were measured in the culture medium using Griess reagents or ELISA kits. Pretreatment with STAT3i and CA inhibited LPS-induced (A) NO and (B) IL-1 $\beta$ expression. Unlike pretreatment of cells with CA, STAT3i did not inhibit the LPS-induced expression of (C) IL-6, (D) TNF- $\alpha$ and (E) MIP-2. Data are expressed as the mean \pm standard deviation of three independent experiments. " $\mathrm{P}<0.05$ and ${ }^{* *} \mathrm{P}<0.01$ vs. LPS stimulation alone. STAT3i, STAT3 inhibitor; LPS, lipopolysaccharide; NO, nitric oxide; IL-6, interleukin-6; TNF- $\alpha$, tumor necrosis factor- $\alpha$; MIP-2, macrophage inflammatory protein-2; CA, chlorogenic acid .

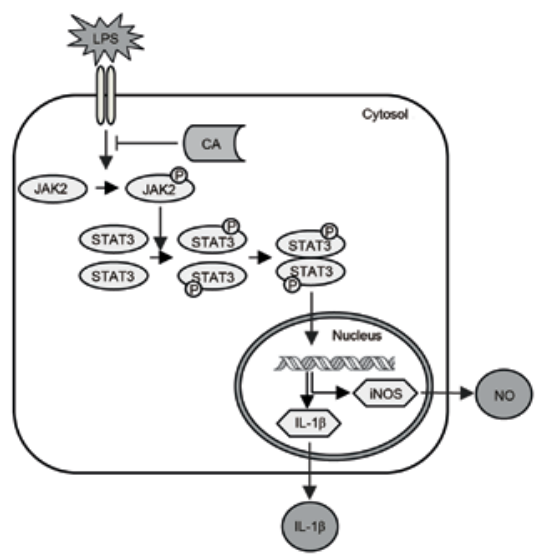

Figure 8. Schematic summarizing the potential underlying mechanism of the anti-inflammatory action of CA. CA inhibited LPS-induced JAK2 and STAT3 phosphorylation, the nuclear translocation of p-STAT3 and the expression of NO and IL-1 $\beta$ in RAW264.7 cells. CA, chlorogenic acid; LPS, lipopolysaccharide; p-JAK2, phosphorylated Janus kinase 2; p-STAT3, phosphorylated signal transducer and activator of transcription 3; iNOS, inducible nitric oxide synthase; NO, nitric oxide; IL-1 $\beta$, interleukin- $1 \beta$.

results suggest that the inhibitory effect of CA on LPS-induced NO and IL-1 $\beta$ expression may be mediated by inhibiting the STAT3 signaling pathway.

Potential mechanisms underlying the anti-inflammatory actions of CA. CA inhibited LPS-induced JAK2 and STAT3 phosphorylation, the nuclear translocation of p-STAT3 and the expression of NO and IL-1 $\beta$ in RAW264.7 cells (Fig. 8). These results indicate that CA may suppress LPS-induced NO and IL-1 $\beta$ expression by inhibiting JAK2/STAT3 activation in RAW264.7 cells.

\section{Discussion}

CA is one of the most abundant polyphenol compounds present in the human diet and is a major constituent of coffee. Previous studies have demonstrated that CA possesses a number of biological properties including anti-inflammatory, antioxidant and anticarcinogenic activities (8). These beneficial effects of CA may be due to its ability to scavenge free radicals, such as reactive nitrogen and oxygen species, and downregulate pro-inflammatory mediators (8-10).

NO is an inorganic free radical, synthesized by NOS. Two major isoforms of NOS have been identified in the intestine, including the constitutive (endothelial NOS) and inducible forms (iNOS). Endothelial NOS is constitutively expressed and is responsible for the maintenance of housekeeping and physiological functions. By contrast, iNOS is overexpressed under pathological conditions, such as inflammation, in a number of cells, which leads to the production of high levels of NO. The production of NO by iNOS and reactive nitrogen species disrupts intestinal barrier function, leading to the increased uptake of luminal antigens, as well as the activation of a dysregulated immune response (24-26). Two different isoforms of COX catalyze the synthesis of prostaglandins from arachidonic acid. COX-1 is known as the housekeeping enzyme, while COX-2 is induced in response to a variety of pro-inflammatory mediators, growth factors and hormones (24-27).

The present study first investigated the effect of CA on the expression of reactive nitrogen species and COX-2 in 
LPS-stimulated macrophages. The results demonstrated that CA inhibited LPS-induced iNOS expression and NO production in macrophages, whereas COX-2 expression remained unchanged.

A number of studies have revealed that the excessive production of pro-inflammatory cytokines and chemokines, including IL- $1 \beta$, IL-6, TNF- $\alpha$, monocyte chemotactic protein (MCP) and MIP, leads to uncontrolled inflammation and tissue injury (12-16). In the present study, CA inhibited the LPS-induced expression of IL-6, TNF- $\alpha$, MIP-2 and IL-1 $\beta$ in macrophages. Similarly, a previous study demonstrated that CA inhibited the staphylococcal exotoxin-induced production of IL-1 $\beta$, TNF- $\alpha$, IL-6, interferon- $\gamma$, MCP-1, MIP- $1 \alpha$ and MIP-1 $\beta$ in human peripheral blood mononuclear cells (28). These results indicate that CA may exert anti-inflammatory activities via the suppression of reactive nitrogen species and the downregulation of pro-inflammatory cytokines and chemokines, irrespective of cell type.

The production of various pro-inflammatory mediators is controlled by the activity of transcription factors and protein kinases, including NF- $\mathrm{B}, \mathrm{MAPKs}$ and JAK/STAT. Consequently, the activation of these transcription factors and protein kinases is important in inflammation-associated diseases, such as IBD, and have been proposed as potential therapeutic targets for IBD (20,21,29-31). A previous study revealed that CA exhibits anti-inflammatory activities by modulating important metabolic pathways (8). It has been previously demonstrated that CA inhibits LPS-induced inflammation in macrophages by suppressing $\mathrm{NF}-\kappa \mathrm{B}$ and MAPK signaling pathways $(32,33)$. In addition, CA exerted beneficial effects in LPS-, dextran sulfate sodium- and trinitrobenzene sulfonic acid-induced colitis in animal models (34-36). Therefore, the results from in vitro and in vivo studies indicate that part of the anti-inflammatory effects of CA may be attributed to the inhibition of NF- $\kappa \mathrm{B}$ and MAPK activities. However, the effect of CA on JAK/STAT signaling remains to be elucidated.

The present study then investigated the impact of CA on LPS-induced NF- $\kappa$ B, MAPKs and JAK/STAT signaling pathways in macrophages. CA reduced the level of p-JAK2 and p-STAT3, whereas the phosphorylation levels of ERK1/2, JNK, p38, IкB $\alpha$ and p65 remained unchanged. The JAK/STAT signaling pathway is an essential inflammatory pathway that mediates immune responses. A previous study demonstrated that JAK/STAT are involved in inflammatory signaling pathways in response to various external stimuli, including LPS, hormones, growth factors and cytokines (19). The binding of ligands to its associated receptors induces JAK phosphorylation and activation. Activated JAK then phosphorylates STAT, which subsequently forms a homo- or heterodimer. These dimers translocate to the nucleus and bind to specific sequences in the promoter regions of target genes encoding pro-inflammatory mediators, including cytokines, chemokines and inducible enzymes, such as iNOS and COX-2 (16-20).

In the present study, STAT3i was used to determine whether the STAT3 signaling pathway may be involved in the anti-inflammatory effects of CA. The results demonstrated that CA and STAT3i inhibited the LPS-induced nuclear translocation of p-STAT3. In addition, LPS-induced expression of iNOS, NO and IL-1 $\beta$ protein was inhibited by STAT3i and
CA pretreatments. However, LPS-induced expression of IL-6, TNF- $\alpha$ and MIP-2 was not inhibited by STAT3i. These results indicate that induction of IL- 6 , TNF- $\alpha$ and MIP-2 by LPS may not be directly affected by the STAT3 transcription factor in the nucleus. Alternatively, the binding of IL- 6 to its receptor may induce phosphorylation of JAK/STAT and its subsequent translocation to the nucleus $(37,38)$.

In conclusion, the results of the present study indicate that CA may suppress LPS-induced NO and IL-1 $\beta$ expression by inhibiting JAK2/STAT3 activation in RAW264.7 cells. Therefore, modulation of this cell signaling pathway by $\mathrm{CA}$ may be beneficial in inflammation-associated diseases, such as IBD.

\section{References}

1. Trendowski M: Recent advances in the development of antineoplastic agents derived from natural products. Drugs 75: 1993-2016, 2015

2. Joo YE: Natural product-derived drugs for the treatment of inflammatory bowel diseases. Intest Res 12: 103-109, 2014.

3. Kim SB, Park SJ, Chung SH, Hahn KY, Moon DC, Hong SP, Cheon JH, Kim T and Kim WH: Vaccination and complementary and alternative medicine in patients with inflammatory bowel disease. Intest Res 12: 124-130, 2014

4. Kang NJ, Lee KW, Kim BH, Bode AM, Lee HJ, Heo YS, Boardman L, Limburg P, Lee HJ and Dong Z: Coffee phenolic phytochemicals suppress colon cancer metastasis by targeting MEK and TOPK. Carcinogenesis 32: 921-928, 2011.

5. Svilaas A, Sakhi AK, Andersen LF, Svilaas T, Ström EC, Jacobs DR Jr, Ose L and Blomhoff R: Intakes of antioxidants in coffee, wine, and vegetables are correlated with plasma carotenoids in humans. J Nutr 134: 562-567, 2004.

6. Ludwig IA, Clifford MN, Lean ME, Ashihara $\mathrm{H}$ and Crozier A: Coffee: Biochemistry and potential impact on health. Food Funct 5: 1695-1717, 2014.

7. Bøhn SK, Blomhoff R and Paur I: Coffee and cancer risk, epidemiological evidence, and molecular mechanisms. Mol Nutr Food Res 58: 915-930, 2014.

8. Liang $\mathrm{N}$ and Kitts DD: Role of chlorogenic acids in controlling oxidative and inflammatory stress conditions. Nutrients 8: pii: E16, 2015.

9. Upadhyay R and Mohan Rao LJ: An outlook on chlorogenic acids-occurrence, chemistry, technology, and biological activities. Crit Rev Food Sci Nutr 53: 968-984, 2013.

10. Weng CJ and Yen GC: Chemopreventive effects of dietary phytochemicals against cancer invasion and metastasis: Phenolic acids, monophenol, polyphenol, and their derivatives. Cancer Treat Rev 38: 76-87, 2012.

11. Kim YJ, Chang SY and Ko HJ: Myeloid-derived suppressor cells in inflammatory bowel disease. Intest Res 13:105-111, 2015.

12. Strober W, Fuss I and Mannon P: The fundamental basis of inflammatory bowel disease. J Clin Invest 117: 514-521, 2007.

13. Podolsky DK and Xavier RJ: Unravelling the pathogenesis of inflammatory bowel disease. Nature 448: 427-434, 2007.

14. Lee SH: Intestinal permeability regulation by tight junction: Implication on inflammatory bowel diseases. Intest Res 13: $11-18,2015$

15. Morris MC, Gilliam EA and Li L: Innate immune programing by endotoxin and its pathological consequences. Front Immunol 5: 680, 2015

16. Han DS: Current status and prospects of intestinal microbiome studies. Intest Res 12: 178-183, 2014.

17. Yu Z, Zhang W and Kone BC: Signal transducers and activators of transcription 3 (STAT3) inhibits transcription of the inducible nitric oxide synthase gene by interacting with nuclear factor kappaB. Biochem J 367: 97-105, 2002.

18. Okugawa S, Ota Y, Kitazawa T, Nakayama K, Yanagimoto S, Tsukada K, Kawada M and Kimura S: Janus kinase 2 is involved in lipopolysaccharide-induced activation of macrophages. Am J Physiol Cell Physiol 285: C399-C408, 2003.

19. Villarino AV, Kanno Y, Ferdinand JR and O'Shea JJ: Mechanisms of Jak/STAT signaling in immunity and disease. J Immunol 194: 21-27, 2015 
20. Zundler S and Neurath MF: Integrating immunologic signaling networks: The JAK/STAT pathway in colitis and colitis-associated cancer. Vaccines (Basel) 4: pii: E5, 2016.

21. Coskun M, Salem M, Pedersen J and Nielsen OH: Involvement of JAK/STAT signaling in the pathogenesis of inflammatory bowel disease. Pharmacol Res 76: 1-8, 2013.

22. Danese S, Grisham M, Hodge J and Telliez JB: JAK inhibition using tofacitinib for inflammatory bowel disease treatment: A hub for multiple inflammatory cytokines. Am J Physiol Gastrointest Liver Physiol 310: G155-G162, 2016.

23. Vuitton L, Koch S and Peyrin-Biroulet L: Janus kinase inhibition with tofacitinib: Changing the face of inflammatory bowel disease treatment. Curr Drug Targets 14: 1385-1391, 2013.

24. Kim SF: The nitric oxide-mediated regulation of prostaglandin signaling in medicine. Vitam Horm 96: 211-245, 2014.

25. Salvemini D, Kim SF and Mollace V: Reciprocal regulation of the nitric oxide and cyclooxygenase pathway in pathophysiology: Relevance and clinical implications. Am J Physiol Regul Integr Comp Physiol 304: R473-R487, 2013.

26. Kim SF: The role of nitric oxide in prostaglandin biology; update. Nitric Oxide 25: 255-264, 2011.

27. Gądek-Michalska A, Tadeusz J, Rachwalska P and Bugajski J: Cytokines, prostaglandins and nitric oxide in the regulation of stress-response systems. Pharmacol Rep 65: 1655-1662, 2013

28. Krakauer T: The polyphenol chlorogenic acid inhibits staphylococcal exotoxin-induced inflammatory cytokines and chemokines. Immunopharmacol Immunotoxicol 24: 113-119, 2002.

29. Wei J and Feng J: Signaling pathways associated with inflammatory bowel disease. Recent Pat Inflamm Allergy Drug Discov 4: $105-117,2010$.

30. Karrasch T and Jobin C: NF-kappaB and the intestine: Friend or foe? Inflamm Bowel Dis 14: 114-124, 2008.

31. Broom OJ, Widjaya B, Troelsen J, Olsen J and Nielsen $\mathrm{OH}$ : Mitogen activated protein kinases: A role in inflammatory bowel disease? Clin Exp Immunol 158: 272-280, 2009.
32. Hwang SJ, Kim YW, Park Y, Lee HJ and Kim KW: Anti-inflammatory effects of chlorogenic acid in lipopolysaccharide-stimulated RAW 264.7 cells. Inflamm Res 63: 81-90, 2014.

33. Shan J, Fu J, Zhao Z, Kong X, Huang H, Luo L and Yin Z: Chlorogenic acid inhibits lipopolysaccharide-induced cyclooxygenase-2 expression in RAW264.7 cells through suppressing NF-kappaB and JNK/AP-1 activation. Int Immunopharmacol 9: 1042-1048, 2009.

34. Ruan Z, Liu S, Zhou Y, Mi S, Liu G, Wu X, Yao K, Assaad H, Deng Z, Hou Y, et al: Chlorogenic acid decreases intestinal permeability and increases expression of intestinal tight junction proteins in weaned rats challenged with LPS. PLoS One 9: e97815, 2014

35. Shin HS, Satsu H, Bae MJ, Zhao Z, Ogiwara H, Totsuka M and Shimizu M: Anti-inflammatory effect of chlorogenic acid on the IL-8 production in Caco-2 cells and the dextran sulphate sodium-induced colitis symptoms in C57BL/6 mice. Food Chem 168: 167-175, 2015.

36. Zatorski H, Sałaga M, Zielińska M, Piechota-Polańczyk A Owczarek K, Kordek R, Lewandowska U, Chen C and Fichna J: Experimental colitis in mice is attenuated by topical administration of chlorogenic acid. Naunyn Schmiedebergs Arch Pharmacol 388: 643-651, 2015.

37. Shen X, Tian Z, Holtzman MJ and Gao B: Cross-talk between interleukin 1beta (IL-1beta) and IL-6 signalling pathways: IL-1beta selectively inhibits IL-6-activated signal transducer and activator of transcription factor 1 (STAT1) by a proteasome-dependent mechanism. Biochem J 352: 913-919, 2000.

38. Shi D, Wang Q, Zheng H, Li D, Shen Y, Fu H, Li T, Mei H, Lu G, Qiu Y, et al: Paeoniflorin suppresses IL-6/Stat3 pathway via upregulation of Socs3 in dendritic cells in response to 1-chloro-2,4-dinitrobenze. Int Immunopharmacol 38: 45-53, 2016. 